\title{
INTEGRATING SUSTAINABILITY WITHIN ARCHITECTURAL EDUCATION IN CAIRO
}

\author{
Sameh El-Feki ${ }^{1}$ Inji Kenawy ${ }^{2}$ \\ ${ }^{1}$ MSA University, Cairo, Egypt \\ ${ }^{2}$ University of Salford, Manchester, UK
}

\section{Keywords}

Sustainable Education, Design Studio, Architectural Curricula, Sustainability;

\begin{abstract}
Architectural education has great potential to move the entire industry towards sustainability within buildings and cities. Having the fundamental knowledge to apply the sustainable strategies can help in solving different environmental challenges being faced today. Sustainability is then recognized as a core topic in architecture and to reflect this recognition, it is crucial to integrate it into the architectural education curriculum. Many approaches are used to introduce the concept of sustainability into the architectural programs ranging from integrating the concept into existing modules to adding new modules that are entirely dedicated towards this subject. The design studio is the most dominant module in architectural education having the highest credit hours per week, and being a pool within which all subjects dissolve. The studio is characterized by creating a unique learning environment modeled around a problem-solving practice. Introducing sustainability into design studio was then found to be a key potential that enables graduate architects to make sustainable decisions within their design process rather than handling it separately. Realizing that potential; architectural educational institutions used different approaches in order to include sustainability within their curricula.

This paper sheds lights on the education of sustainability within the architectural curricula in a number of Egyptian universities. It discusses the teaching and learning of sustainable design then, identifies and analyses different approaches used in integrating the concept of sustainability into the curriculum. Follows, a qualitative analysis takes place from a semi-structured interview conducted to practitioners and educators from various universities in order to stand on methods used to integrate sustainability into their architectural curricula. The findings are to develop recommendations that could help discovering the best practices that could enhance the learning experience for integrating sustainability in design studio modules.
\end{abstract}

\section{Introduction}

The sector of building construction is known to be accountable for various environmental impacts. As part of this sector, architecture has great potential to move the entire industry towards sustainability within buildings and cities by providing the necessary information that could help professionals responding to the current environmental challenges. The International Union of Architects (2008) identified that one of the main two goals of architectural education is to generate intellectual maturity, ecological sensitivity as well as social responsibility among citizens. It is important for future architects to be aware of the impact of their thoughts and actions on the future of their surrounding environment and community (Shari and Jaafar, 2006).

Although integrating sustainability into architectural education is found to be quiet significant, different resistances were found including the willingness of educational system and the teaching methods. Different universities have been willing to involve sustain-able environmental education into the architecture discipline. However, as stated by Olweny (2016) other universities resisted the idea claiming that the current crowded curriculum was unable to include the sustainable environmental education. Others argued that this addition is not to be included in the architectural 
education and added that they are to be considered after mastering the core aspects. He (2016) added that some regions including East Africa also considered that the concept of sustainability only belongs to developed countries claiming, "Our concern is for development, and this sustainability thing will drive up this cost". Adjusting the existing busy curricula to achieve integrated teaching is another challenge, especially with the ambiguous nature of the term sustainability. Covering the different pillars of sustainability including environmental, social, economic, and cultural is another complexity facing the change in the curricula. As Altomonte, et al. (2012) explained, solving these concerns is subject to the legislation, professional qualification criteria, as well as the accreditation frameworks; which are the main responsible factors of integrating sustainability within architectural education. This would by its turn facilitate knowledge transfer between the theory and practice and relate it to the sustainable concepts.

This paper is concerned with the Egyptian Architectural Education and aims to investigate integrating sustainability within architectural curricula in a number of universities. The current situation of the curricula will first be surveyed. Accordingly, the paper will examine the different opportunities and constraints facing the process of integrating sustainability with architecture curricula. The findings will then propose recommendations that could be applied in order to promote such integration.

\section{Literature Review}

Integrating the concept of sustainability within architectural education became a vital necessity for a promising future. Accordingly, different efforts were taken into practice to achieve this kind of integration. Since 2004, the concept of sustainability was included within the Conditions for Accreditation for Professional Degree Programs in Architecture in the U.S.A. (Adegbile, 2012). The main focus was increasing the awareness of the effect of architecture and urban design decisions on building a healthy environment (NAAB, 2004). Creating a "carbon neutral design resources for educators and professionals" is another attempt launched through the collaboration between the US Educators Practitioners Network, the Society of Building Science Educators, the AIA Committee on the Environment, and the AIA Sustainability Discussion Group (Boake, 2008). A series of workshops named "Designs of the Planets" also took place in the United Kingdom to address this challenge taking into account the environmental awareness of the future architects. The workshops were supported by the Centre for Education in the Built Environment (CEBE) and the Royal Institute of British Architects (RIBA); and included Oxford Brookes University, the University of Nottingham and Cardiff University (Stevenson, et al., 2009, Adeg-bile 2012).

The United Nations, Guidelines on Education Policy for Sustainable Built Environments also endorsed the role of universities towards sustainability and encouraged to develop relevant strategies through teaching and research (UNEP, 2010). The Environmental Design in University Curricula and Architectural Training in Europe (EDUCATE project) funded by the European Commission - Energy Agency for Competitiveness and Innovation (EACI) also aimed to address this matter. The project's duration was carried out from June 2009 to May 2012. It focused on developing guidelines to help to support the integration of sustainability in the teaching and practice of architecture. Their actions involved developing university curricular analysis methods, which concentrate on sustainability and energy efficiency teaching. The methods varied from verifying working class hours to the theme and integration with design studio models of seven curricula of Architecture in Europe (EDUCATE, 2011, Dourado \& Amorim, 2016).

\subsection{Approaches to Introducing Sustainable Environmental Education in the Architecture Curriculum}

Different approaches have been identified in introducing sustainability into architecture curriculum. In his attempt to examine combining sustainability into architectural education in the United States, Wright (2003) differentiated between three different methods of integration. The first method assumes that the nature of sustainability permits its embedment in all the different modules of architectural curricula. This method embraces the idea of sustainable design being so essential to architecture, to the extent of being incorrect to separate it from the actual theory and practice. EDUCATE (2011) identified two curricula structure in this method named the linear and the fully integrated structures. In the linear (parallel) model sustainability knowledge proceed in parallel to the different modules, however, the fully integrated structure focuses on the design studio modules and perceives them as interdisciplinary working places. The main concern in this method is relying on the assumption that all teaching staffs are well aware of the complexity of sustainability, which will allow genuine improvement of the curricula. The second method seeks to expand the existing modules in order to include the environmental control systems. This partially integrated structure allows identifying the different techniques used in buildings in order to create environmentally comfortable spaces for users in the design studio modules. Likewise, the fully iterative structure in which there is an apparent interdependency between the environmental science and design studio modules (EDUCATE, 2011). The curricula, in this case, remain mostly the same, however, focusing on emphasizing the themes relevant to environmental control systems in the different modules including the design studios. This method is more beneficial for faculties having more awareness of the technical aspects of environmental control; however, it's limited to individuals who might not be leading the design theory and studios in the curricula (NCARB, 2000; Wright, 2003). Alternatively, a similar technology domain method was proposed in which sustainability knowledge required for architecture students could be addressed in environmental systems modules (Iulo et. al, 2013). The third method adopts the idea of reviewing the whole curricula in order to fully integrate sustainability into its different modules (Wright, 2003). Iulo et. al (2013) 
named this method the "core value" and added that in this case sustainability is to be addressed in all the modules of architectural education curricula. Considering sustainability as a choice and specialist knowledge were two other methods proposed. The optional (elective) method considers sustainability as a topic that could be selected based on students' preferences (EDUCATE, 2011; Iulo et. al, 2013). On the other side, the specialist knowledge method treats sustainability as a specialized topic that is to be educated in specific graduate degrees (Iulo et. al, 2013).

\subsection{Criteria for Ensuring the Integration of Sustainability in Architecture Curriculum}

Different types of criteria were also offered to be applied as a basis to facilitate the process of integrating sustainability into architecture curricula. Wright (2003) proposed twelve criteria that included encouraging the social engagement and connection with the intimate and global community, opening opportunities to study and travel abroad, interacting with other disciplines and reinforcing the skills of working and cooperating within a team. Working in line with environmental and cultural contexts in the different history and design modules is also to be highlighted. Similarly, Iulo et. al (2013) mentioned that sustainability is a focal point that should be integrated into the different social, theoretical, technical, and aesthetic components of the curricula. They added that adjusting the current theory, studio, and environmental systems modules is an easy and quick approach to changing. It's very important to include the whole building work process in the design studios as the students need to be aware of the relevant materials and the physical aspects. Renewable energy sources are also to be the center of the different technology courses. Some aspects are also to be taken into consideration in the design studio including starting with defining environmental terms like thermal transfer, day-lighting, and air movement before working with the actual activities of the studio (Wright, 2003). Correspondingly, Iulo et. al (2013) stated that sustainable education is to be divided into core modules that establish the baseline to the different sustainability aspects and specialized elective module building on them. EDUATE (2011) proposed an integrated cognitive framework based on the "knowledge triangle" modeled by Simos Yannas at the Architecture Association's MSc \& March in sustainable Environmental Design (AA, 2010). The model consisted of three main categories including the issues and principles; applications and case studies; as well as tools. Wright (2003) also stressed on combining seminars and handouts related to the social and natural knowledge of the surrounding and global region and community. All the faculty members are also to participate in reviewing the whole curriculum for the sustainable discipline to be integrated in a clear and concise way. Finally, the accreditation organizations, as well as the architecture licensing boards, are to ensure that future architects have the necessary skills and body of knowledge for the concept of sustainability.

\subsection{The Profile of Architectural Education in Egypt}

In Egypt, the architectural education can be taught in the architectural departments within faculties of Engineering or the Architectural department within the faculties of fine arts. There are around thirty universities offering this discipline. The faculties of Engineering can be found in public and private universities; however, the faculty of fine arts exists only in public universities. Both public and private universities obtain their graduation certificates from the supreme council of universities and get the membership of the syndicate of Engineering in Egypt. In addition to these benefits, some private universities get validation to their certificates from foreign bodies (both academic and professional) especially the United Kingdom, and some of them even get the Royal Institute of British Architects (RIBA) certificates.

The concern of integrating Sustainability into architectural education has been occupying many Arab educators. Eltouny and AbdelKader (2003) declared their concern on graduating future architects who are unaware of their local challenges. Salama and Abdelgader (2005) also stressed the importance of integrating the environmental aspects into the design studio modules.

In her attempt to examine how the social and environmental aspects are highlighted in the undergraduate studies of Architecture and urban design discipline in Egypt, taking Ain-Shams University as a case study, Dessouky (2016) concluded that the two aspects are quiet margined. She added that some environmental modules were added in 2013 curricula and other social modules were deducted, which might be related to the global concept of environmentalism that was circulated during the 21 st century. She added that the majority of reading lists are related to western sources which might affect the future architects' capabilities to meet the local social and environmental challenges. The credit hours dedicated to the environmental and social modules were also found to be minimal when compared to the design studio modules. However, these aspects could be integrated with the design studio in order to overcome this shortage. The author recommended that the environmental and social learning is to be core modules instead of elective; they are to correspond to the governmental national development plan and connect to their surrounding local community.

\section{Empirical Study}

Having, in the previous section, addressed the theories and paradigms of integrating sustainability in architectural education, this section aims to explore their relevance to different architectural schools in Cairo.

The research adopts a qualitative approach employing semi-structured interviews as the main method of data collection, aiming to elicit views from the interviewees (Creswell, 2003). In such interviews, the interviewer 
formulates a number of open-ended questions, which should be flexible to allow the respondent to develop thoughts and speak expansively about the notions raised, using their own words, developing their own ideas, and expressing their own perspectives (Bryman, 1995). In this regard, Denscombe (1998) verifies that this technique provides a better opportunity for in-depth study, especially those which are related to personal experiences. Thus, thirteen questions are included. These involve a thorough investigation and the subjects' viewpoints about sustainability, architectural education, and the relationship between both.

\subsection{The Sample}

The study utilized the 'purposive sampling' technique. Denscombe (1998) suggested that this technique applies to those cases where the researcher already knows something about the subjects or events and intentionally selects specific ones because they are expected to have critical views and come out with valuable data, because of their involvement in the area of the study. In such cases, conventional 'prob-ability sampling' may not be helpful.

Based on the main objectives of this paper, specific guidelines were formed in order to choose the subject sample for the interviews. The research explores the integration of sustainability into architectural education, which gives the first guideline; the study is dealing with members of the architectural community (both academic and practice), having enough knowledge being involved in the area of the research. In addition, and based on EDUCATE (2011) and Iulo et. al, (2013), the researchers nominated the sample to be from institutes that may cover as much of the mentioned models as possible.

Although it is recommended to include between 30 and 250 subjects in surveys, there is different size and logic when it comes to qualitative research, as a small size is quite accepted in qualitative studies (Denscombe, 1998).

In order to ensure that the different academic levels of the community's population were sufficiently represented in the sample of the survey, the community was divided into five categories: faculty members, lecturer assistants, teaching assistants, senior students, and practitioners. The final number of subjects was (16) from six different institutes, covering both types of education public and private. The sample varied according to the occupation of the subjects, which represents their academic level / held degree: ("Faculty Members" - Ph.D. holders), ("Lecturers Assistants" - Masters holders), ("Teaching Assistants"- Bachelor holders), "Senior Students" and "Practitioners". These various characteristics helped to avoid bias in the sample. It is noteworthy to mention that most of the subjects were exposed to more than one experience (public/private; Egyp-tian/Abroad; academic/practice, etc.).

Table 1. Distribution of Respondents by Education

\begin{tabular}{|c|c|c|c|c|c|c|}
\hline Occupation & $\begin{array}{c}\text { Faculty } \\
\text { Members }\end{array}$ & LAs & TAs. & $\begin{array}{c}\text { Senior } \\
\text { Students }\end{array}$ & $\begin{array}{c}\text { Practitio } \\
\text { ners }\end{array}$ & Total \\
\hline Number & 8 & 2 & 2 & 2 & 2 & 16 \\
\hline Percentage & $50 \%$ & $12.5 \%$ & $12.5 \%$ & $12.5 \%$ & $12.5 \%$ & $100 \%$ \\
\hline
\end{tabular}

Source: The authors.

The above table shows the number of respondents associated with the subjects' occupation (academic level), to illustrate the proportions of each category involved in the interviews. Larger numbers of faculty members were included due to their wider experiences.

It should be noted here that one major difficulty the researchers faced during the conduction of the interviews was the arrangement of long meetings at times that suit the researchers and the large number of interviewees, which prevented the involvement of a larger number of the sample, especially the only 'two respondents' categories.

\subsection{Findings and Discussion}

We do not inherit the earth from our ancestors, but we borrow it from our children". (Ancient Indian Proverb).

The following section introduces interpretations and discussion of the notions raised by respondents. The goal is to derive the general theme of integrating sustainability in architectural education specialists have in mind.

It is noteworthy that qualitative research is basically interpretive, i.e. the researcher should make an interpretation of the acquired data throughout the different stages of the survey (Creswell, 2003). However, it is thought that the researcher's self-plays an important role in the interpretation of the qualitative data. The researcher's identity, backgrounds, beliefs, values, and experiences cannot be excluded from the process (Denscombe, 1998). In this regard, Mertens (2003) states that not separating between the personal self and the researcher self, signifies honesty and openness to research.

Interviews started with an introductory question about the importance of integrating sustainability into architectural education. Responses validated the idea of applying such integration. The vast majority of the respondents depicted sustainability as a necessity, not a luxury being a holistic concept that should be incorporated and integrated with all 
curricular developments to the extent that it can be addressed at several levels, for example, one respondent argued that sustainability is inseparable from all disciplines, as it is already part of everything. It is actually, an umbrella under which everything goes. Architecture is one discipline that is directly related to environmental studies and accordingly sustainability. In fact, sustainability is a holistic notion that needs to be integrated conceptually and principally in education and incorporated in practice.

One valid opinion saw architecture is about making people happy; respecting the context; responding to the environmental issues; less carbon emission; preserve energy resources, etc. and obviously this is sustainability.

Another viewpoint looked at it from the perspective of being a mindset for all students and practicing architects suggesting "sustainability is not only solar panels, wind turbines or material it is much more than that" also "it is not that you add sustainability after finishing your design" and "design problems with environmental solutions are sometimes successful, but far much better to design environmentally in the first place".

Others reflected upon it from the job market's point of view advocating that if we looked at schools abroad and careers or jobs in general, being very pragmatic, there is a booming trend in the job market in both fields: sustainability and digital computation design. Therefore, it is necessary to integrate all levels of sustainability (environmental, social and economic, in addition to resources and energy aspects) within the architectural curriculum to prepare students for the job market, and it should be thought of throughout the whole curriculum, not just a course. This was clarified by one of the respondents with the following statement: "It is known that energy consumption in buildings is about $40 \%$, which means that architects are responsible for that sum". Another faculty verified this saying "buildings could positively contribute to the environment in terms of energy consumption. Yet, it could be severely problematic" and "architects are responsible for their actions with its consequences on the surrounding environment".

The second part of the interview studies how a number of Cairene schools of architecture integrate sustainability into their curriculum. This is done without mentioning the name of the institute to respect the request of some of the interviewees of keeping their anonymity, bearing in mind that what really matters here is not the name as much as respondents' ideas, wider and deeper notions, methods, reasons and the insights. Thus, the institutes will be referred to as school 1, school 2, school 3, etc.

School 1: Sustainability is integrated into the curriculum on three levels as a holistic concept that applies to every architectural practice. First, it is incorporated in all design studios; second, there is a theoretical course that provides the basic principles of environmental studies; third, elective courses for students who really want to take a further step in this field. The strategy here is that each level complements the others, laying the concrete foundation for dealing with sustainability, adopting a holistic approach. On the other hand, one expected drawback is that students may not manage to relate courses together, and this is where the tutors' role arises, they can easily deal with this threat by always referring to the other related courses as needed.

Keeping an eye on the design studio, one faculty stated "In order for us to know to what extent this method is working well, we keep an eye on students' design work, if they are incorporating the ideas of sustainability into their designs then the method is successful. The reason why because it is known that design studios are the synthesis of all acquired experiences; they are the culmination of all educational attainment.

Referring to 'Educate' project (EDUCATE, 2011; Iulo et. al, 2013), respondents of this school classified their program as fully integrated, while others saw it as parallel.

School 2: Sustainability is an integral part of the curriculum. It is the main theme of one of the design studios, in addition, there is a theoretical course that introduces the foundations of environmental sustainability precedes this design studio. Sustainability has the attention of the department as there is a dedicated advisor for sustainability in the graduation project studio. Stating a conclusive remark, one faculty noted "In general, sustainability should be infiltrated with different dosages at different stages. That it is why it is believed that sustainability becomes part of the students' mindset, to the extent that some students claim that sustainability should be integrated with a lighter dosage in earlier design courses".

The curriculum of this school also varies between being fully integrated and adopting the parallel model with respect to 'Educate' classification (EDUCATE, 2011; Iulo et. al, 2013).

Interestingly, two respondents were a bit concerned to use one of the given definitions and tried to maneuver around as "mostly integrated". The rationale here was based upon different activities conducted in that regard not on the academic level only, but this is a strategy that was adopted by the university's administration (e.g. extra curriculum activity, public lectures, research project, sustainability construction award, campus's policy for reducing carbon footprint, raising awareness of the whole university's community about this issue and what they should do reaching the very lower level of recycling carpool -mindset of the students and the whole community, etc.).

School 3: One interviewee showed dissatisfaction saying "generally, sustainability is not deeply integrated into the curriculum; it depends on the course instructor to a far extent. Yet, it became a focal point in the curriculum of the credit hours system, which has integration with other disciplines as well. As for the graduation project, there are thematic approaches and it all depends on the advisor whether or not to integrate sustainability, but, unfortunately, it 
is not inherent with the mindset of the program". He resumed saying that there is a post-graduate program called 'building sciences', which is very much related to environmental aspects. Interestingly, students were seeking integration between sustainability, building technology and digital methods; between environmental and computational aspects, which looks promising. In other words, students are seeking optimization in that regard.

Obviously, there are three different curricula in this school, when asked about their categories in relation to 'Educate' research (EDUCATE, 2011; Iulo et. al, 2013), respondents agreed that the original curriculum is weakly integrated (which is out of 'Educate' scale), basically because the integration is so weak to the extent that it does not lay down any of the given umbrellas. The second program is the credit hour system, which is classified as 'core value' because sustainability was one main pillar upon which the whole curriculum was built. The third program is the postgraduate program, which was easily classified as 'specialist knowledge'.

School 4: The curriculum is not that much open to sustainability. The current curriculum goes back to 2003; by then sustainability was not a major point of concern. This curriculum had one theoretical course with no any applications. Logically, the curriculum should be updated to cope with this vital progress, but for some reason, there is resistance towards achieving that. Opposing opinions claim that any upgrades could take place within the design studio, which leaves it to the decision of the instructor that might take place in one studio and not for the others, or may take place in one semester but not always. One of the respondents believed that "the environmental control (theoretical course) should be upgraded to include green architecture and sustainability. In its methodology, it should encourage students to research. Then, it may be taken to the application level through a design studio; bearing in mind that design studio cannot cover the theoretical part on its own". It is also suggested that it is better to separate the theoretical course rather than being incorporated in the design studio because time is very tight in design studios and it is barely enough for the students to produce mature projects. Also, studios are congested (high number of students).

What is noteworthy here is that this area is highly demanded by postgraduate students, but unfortunately, this area suffers being understaffed. On the other hand, the credit hours system curriculum has a strong sustainability stream starting as early as year one. This is done through a horizontal coordination between theoretical courses and the parallel design studio, where students are asked to apply the theoretical concepts on their design within the theoretical course and then include it into their final design studio pinups.

Again, relating the three programs of this school to 'Educate' (EDUCATE, 2011; Iulo et. al, 2013), interviewees were on an agreement that the original curriculum is 'partially integrated'. The credit hour system, on the other hand, is classified as 'core value' because sustainability was a cornerstone of the curriculum, and the strong coordination mentioned earlier. The postgraduate program, regardless the problem of being understaffed, but it is categorized as 'specialist knowledge'.

School 5: The curriculum is based on a British partner's curriculum, which is well planned and focuses on management, sustainability, and green architecture as well as IT. In addition, there is an elective course that digs deeper in this area. The British partner keeps monitoring the process, the thing that maintains quality and continuation.

Green pyramid standards are being taught as means to assess sustainability in terms of the site, energy consumption, thermal comfort, design aspect, management, etc. In this regard, the interviewee claimed: "In fact, it should be part of the evaluation criteria of all courses not only design studios that is how it may become built-in component". It was also mentioned that architecture students should manage their designs to have sustainability emerging from within their designs, and it is not that they finish designs and then add the sustainability layer. Following the 'Educate' scale (EDUCATE, 2011; Iulo et. al, 2013), respondents believed that this program is adopting the parallel model.

School 6: On top of the environmental control course, there are several other electives that are relevant to sustainability. Furthermore, it has a good attention of the graduation project team with its two parts the research and the design. It should also be stated that the issue of sustainability is incorporated in design studios, each level with the appropriate dosage. However, this is not constantly done, which made weak students turn their backs on it, unlike good students who take it seriously.

Environmental control course used to be in the fourth year. In the new curriculum, it was moved to the first year to get this important issue introduced to students at an early stage to allow them to utilize it in their design 1 in the short term and get used of it in their future design studios on the longer term. The respondent resumed saying that "the department is very keen on applying horizontal coordination, as Design 1 students can now accommodate parts of climate analysis and apply some of the passive design strategies. Active systems, renewable power generations come at a later stage". Another faculty member claimed that environmental control course ends up with design recommendations to be applied in the design studio. Obviously, design 2 is a better opportunity to get this privilege. When asked the usual question about how respondents of this school relate their curriculum to 'Educate' project (EDUCATE, 2011; Iulo et. al, 2013), the responses were divided into two phases the old phase, which was only based on the 'Environmental Control' course and elective courses and the current phase which is previously mentioned. As for the first phase, they agreed that it can be classified as a combination between 'partial integration' and 'electives'. While the current phase did not have the same agreement, as part of the respondents considered the curriculum as a mix between 'parallel' and 'iterative' models, whereas the rest saw it as 'fully integrated' model. 
The second 'Educate' related issue discussed the three main categories (Issues and Principles; Applications and Case Studies; Tools), when is it best to address each. A number of respondents argued that these look like phases to them and their sequence makes sense. They carried on saying that "issues and principles" should be addressed during the first two years of the program. Then "applications and case studies" for the intermediate stage of the study. Finally, the whole process should be culminated by tools in the last year including (software and simulation tools). More specializations may take place in postgraduate studies.

On the other hand, one respondent stated that they are not separable, they should run in parallel all the time but you design the curriculum to allow the right dosage at each level. The threat of dealing with them as sequential phases is that students may get used to designing their projects without considering sustainability and they grow up with this as a luxury rather than a necessity.

Interestingly, one of the student stated that they should be sequential in terms of the mentioned phases, but parallel in terms of application, meaning that each design level should take the appropriate dosage of sustainability following this sequence, starting with theoretical part (principles) and continues till (tools), so they are all incorporated into the design studio. In other words, they are divided into phases within the same design studio.

Practitioners, on another hand, stressed the importance of sustainability as a concept to be taught to students. It is argued that it should be integrated with higher design studios, not all of them as it may limit creativity and innovation. Interestingly, both practitioners suggested that "the curriculum should not only consider teaching students how to design environmentally, but also have to teach them methods of turning already existing buildings into a sustainable one through different treatments and add-on materials (e.g. retrofitting solar panels, adding Miramax boards on walls, v-cool alloys to be stuck on glass to reduce energy consumption, etc.)". They've also claimed that this would be an essential need throughout the forth-coming period due to the current economic situation in Egypt which led the government to reduce the funded support given to all energy resources (electricity, fuel, etc.).

They added that sustainability is not fixed; on the contrary, it is dynamic and is always in a process of development responding to the daily life changeable needs. It is something that we should live and should keep an eye on its transformation, not to narrow it down to be just a checklist. It should be dealt with on both the micro and the macro levels, with the possibility of going forth and back between them.

When asked about the constraints resisting the process of integrating sustainability into architecture education, responses were diversified and informative. These could be summarized into five main issues. First: the gap between architectural education and practice, which may give the opportunity to some institutions to deal with sustainability as not being a major player in their education. This gives an impression that it is a luxury option or theoretical not practical. Hence, sustainability should be part of the present market requirements. If the practice were more related to education, then people would be more keen on such notions. For example, LEED should be a necessity for building codes rather than being a mandatory course. Second: the community's ignorance is a major constraint. Awareness should be created and promoted to the whole community about the three aspects of sustainability (social, economic and environmental). This also includes instructors who don't see the point as they don't see it important. This is may be due to: cheap electricity rates; geographical location of Egypt which made the good ventilation direction the same as good daylight, no swings in temperature. Maybe one good way of raising the awareness of the architectural society is to ask students to design in other countries were these aspects might vary i.e. cold area passive heating systems rather than only passive cooling systems in arid areas. Third: sustainability used to be qualitative (just guidelines), nowadays it became quantified, measurable and computer oriented, that is why resources developed to be another constraint; a lot of (expensive) equipment is needed e.g. labs, environmental examination tools, software, simulators, not to mention the human resources exemplified in qualified faculty, otherwise it is all theoretical. Fourth: not many courses could be added to the curriculum because the total credit hours could not be increased. Last but not least, a large number of students within cohorts, which prevents field visits and internships.

\section{Recommendations}

The study illustrates that there is a general agreement on the significance of integrating sustainability within architectural education. Accordingly, and to improve and maintain such integration, and in the view of the above findings, the study presents a set of recommended actions.

- From a wider perspective, it is suggested that sustainability should be dealt with as an interdisciplinary collaboration between different fields. In addition, it is highly recommended to involve policy makers and administration because willingness coming from the administration will definitely help in raising the awareness of the whole university's community about sustainability through workshops and campaigns, which will trigger people to think, and consequently becomes part of the mindset. In parallel, researchers should be encouraged and funded.

- As for the practice, it is suggested that it should be part of the permit requirements and each building should have an ID. Prior to this step, incentives should be announced to landlords, i.e. add to the allowed built-up area if the building is more sustainable. 
- - When it comes to curricula, the first thing to be done is to update and upgrade old curricula, to cope with the current society requirements. Attention should be paid to how to infiltrate sustainability in the whole curriculum until the very end, then monitor and track it.

- - It is suggested that one good way to integrate sustainability within architectural education is through the following routes: First, to balance between the qualitative and the quantitative approaches, meaning to keep the qualitative at the very early years as an introduction; and to pay more attention to the quantitative, which gives information that facilitates the decision making process.

The second route is to look into both the vertical and the horizontal coordination between different courses. Vertically, plan what, how and when should each part of sustainability introduced to students. While horizontally, conduct a series of courses/lectures that complement design studios and other courses (e.g. working drawings) on different levels. The difficulty may be faced here, is the limitations of increasing the number of credit hours in the curriculum. To overcome it, it is believed that it would be helpful if spreading sustainability among all design studios with different dosages, different capacities, different approaches, different complexities, and with the needed theoretical introduction, varying from climatic issues to building materials, appropriate building technologies, renewable energy resources (wind/ solar) each to be accommodated within the appropriate level. Bearing in mind that it should be dealt with as a holistic system, that encompasses the trio (social, economic as well as passive and active environmental systems). This may start at lower design studios going through the following studios, to make a continuous thread till the graduation project and have a special sustainability advisor. This should be applied not only on design studios but on other disciplines as well, including building construction, history, and theories, project management courses, etc.

Hence, students should be able to deal with sustainability as an integral part of the design is one of the main parameters, the same as structure, context, etc. It should be clearly known that it is not a sugar-coated or an add-on layer to projects, instead, sustainability should be well integrated and emerging from the design itself. Then it becomes a mindset for the students.

However, one has to pay attention to the fact that sometimes examination tools limit the outcome, the ideas, and creativity accordingly. The threat here is that in design studios when having the same tool with the same limitations may end up having similar projects. Therefore, the followed approach should be process driven rather than product driven.

The third route is to plan for the specialty area of advanced topics in sustainability in the postgraduate program.

- One other important point that should be considered is to add courses to the curriculum that teach students how to turn an already existing non-sustainable building into a sustainable one, particularly when it comes to energy saving and carbon emission reduction.

- In regard to staff, they have to adapt what's new and create awareness to the community. In fact, qualified staff is a corner-stone in this process. That is why universities should pay attention to this issue and hire experts in the area of sustainability. Generally, staff should encourage students to dig deeper and allow them to innovate rather than refusing their work asking them to stick to traditional systems.

\section{Conclusion}

This paper was intended to study the integration of sustainability within the architectural education in Egypt / Cairo. To achieve this, a two-phase methodology was employed. It started by laying down a foundation based on a literature review discussing different approaches to such integration distilled from international experiences. The second phase, comprising the empirical part, the study examined the Cairene context utilizing qualitative semi-structured interviews. These were conducted by practitioners and educators to stand on the experiences of six different institutes. This investigation was intended to elicit the current experiences, applied methods, advantages, and disadvantages, opportunities, and constraints, in addition to suggestions to enhance the process. Hence, the study could stand on good and problematic areas, and thus culminate it by recommendations that could help improve the learning experience for integrating sustainability in architectural education.

It is the study's finding that in spite of the efforts exerted in this regard, i.e. producing GPRS (Green Pyramid Rating System - Egyp-tian LEED), but these are not enough. Academically, all participants are in agreement that integrating sustainability concepts within the architectural curricula is a crucial matter that has to be implemented, continually monitored, tracked and updated. In other words, sustainability will inevitably happen, the government may mandate it at a point of time, and becomes a bylaw action, basically, because of the resources issue and that the government is stopping the financial support of energy sources. If the decision is taken sustainability will definitely flourish and schools have to be well prepared for this step. Furthermore, it is realized that being exposed to other international experiences; in addition to joint programs and the cooperation with foreign universities mandates expansion of such type of education, to the extent that it becomes part of the mindset of the whole community.

Finally, it is highly hoped that Egyptians schools of architecture would make good use of the study's findings and recommendations, which are intended to improve and enhance the integration of sustainability within architectural 
education, to produce sustainable sound building environment, and ultimately raise the awareness of the community about sustainability to act sustainably.

\section{Acknowledgment}

The authors would like to thank all contributors who agreed to be part of the interview; as their informative insights added a great value to this research.

\section{References}

1. AA, Architecture Association (2010) MSc \& March Sustainable Environmental Design, Programme Guide 2010-11. Environmental \& Energy Studies Programme. [Online] Available: http://www.aaschool.ac.uk/ee

2. Adegbile, M., Nigerian architectural education in a sustainable age, in Sustainable Futures: Architecture and Urbanism in the Global South Kampala, Uganda, 27 - 30 June 2012.

3. Altomonte, S., Rutherford, P., Wilson, R., 2012, "Mapping the Way Forward: Education for Sustainability in Architecture and Urban Design". Corporate Social Responsibility and Environmental Management, Vol. 21, No. 3, 143 - 154.
4. Boake
T.M.,
(2008)
Carbon Neutral
Design
Project. [Online]

http://www.sparksdesigns.co.uk/workingfiles/bluezulu/oxfordconference/presentations/pdfs/01_3_2.pdf (November 1, 2016)

5. Bryman, A. (1995) Quantity and Quality in Social Research, Lon-don: Routledge.

6. Creswell, J. W. (2003) Research Design: Qualitative, Quantitative and Mixed Methods Approaches, London: Sage Publications.

7. Denscombe, M. (1998) The Good Research Guide for Small-scale Social Research Projects, Buckingham: Open University Press.

8. Dessouky, N. (2016) Architecture and urban education in Egypt: producing designers that are ready to respond to the social and environmental circumstances of the Egyptian context. Procedia Environmental Sciences Vol. 34, $401-410$.

9. Dourado, B. M., Amorim, C. N. D., (2016). Environmental sustainability Education in Brazilian Architecture and Urbanism courses: evaluation and subsidies.in PLEAPassive Low Energy Architecture Conference 2016, pp. 257.

10. EDUCATE - Environmental Design in University Curricula and Architectural Training in Europe, 2011. Framework for Curriculum Development [Online], Available: www.EDUCATE-sustainability.eu [03 October 2016].

11. Eltouny, S., AbdelKader, N. (2003) Transforming Architectural Education in Developing Settings; Amidst' Global Stresses and Contextual Limitations. Architectural Education for the New Millennium Issues, Innovations, and Traditions, Alexandria, Egypt.

12. International Union of Architects (UIA). (2008). UIA and Architectural Education Reflections and Recommendations. Paris: International Union of Architects.[Online], Available: http://www.aij.or.jp/jpn/aijedu/reflex_eng.pdf.

13. Iulo, L. D., Gorby, C., Poerschke, U., Kalisperis, L. N. and Woollen, M. (2013),"Environmentally conscious design - educating future architects", International Journal of Sustainability in Higher Education, Vol. 14, No. 4, 434 - 448

14. Mertens, D. M. (2003) "Mixed methods and the politics of human research: the transformative- emancipatory perspective" In A. Tashakkori and C. Teddlie (Eds.) Handbook of Mixed Methods in Social and Behavioural Sciences, Thousand Oaks: Sage.

15. NAAB National Architectural Accrediting Board. (2004) NAAB Conditions for Accreditation for Professional Degree Programs in Architecture. New York: AIA.

16. National Council of Architectural Registration Boards (2000), NCARB Education Standard, National Council of Architectural Registration Boards Mission Statement, Washington, DC.

17. Olweny, M, (2016).That is Too Radical For Us: Sustainable Design Education in East Africa, PLEA Passive Low Energy Architecture Conference 2016, Los Angeles, p. 1856

18. Salama, A., Abdulgader, A. (2005), Paradigmatic trends in Arab Architectural Education: Impacts and challenges, Congress of the International Union of Architects, Istanbul, UIA.

19. Shari, Z. , F. Z. Jaafar (2006). Integration and Implementation of Sustainability in Malaysian Architectural Education. In the 40th Annual Conference of the Architectural Science Association AN-ZAScA, 22-24 November 2006 Adelaide, Australia.

20. Stevenson, F., Roberts, A., Altomonte, S. (2009).Designs on the Planet. A workshop series on architectural education and the challenges of climate change. In PLEAPassive Low Energy Architecture Conference 2009, 22-24June 2009, Quebec, Canada.

21. UNEP - United Nations Environment Program, 2010. Guidelines on Education Policy for Sustainable Built Environments. [Online], Available: http://www.unep.org/resourceefficiency/Publications/Publication/tabid/444/language/en-US/Default.aspx?BookID=4182 [22 October 2016].

22. Wright, James (2003), "Introducing sustainability into the architecture curriculum in the United States", International Journal of Sustainability in Higher Education, Vol. 4, No. 2, $100-105$. 